\title{
RETROSPECTIVE ANALYSIS OF OPHTHALMIC AILMENTS IN CHILDREN ATTENDING THE CHILD DEVELOPMENT UNIT IN A TERTIARY CARE HOSPITAL IN SOUTH INDIA
}

\author{
Mary Thomas ${ }^{1}$, Vaishnavi R2, Gayathri N³, M. Muthayya ${ }^{4}$, Binu Ninan 5 \\ ${ }_{1}^{1}$ Associate Professor, Department of Ophthalmology, Sri Ramachandra Medical College and Research Institute, Porur, Chennai. \\ ${ }^{2}$ Senior Resident, Department of Ophthalmology, Sri Ramachandra Medical College and Research Institute, Porur, Chennai. \\ ${ }^{3}$ Post Graduate Student, Department of Ophthalmology, Sri Ramachandra Medical College and Research Institute, Porur, Chennai. \\ ${ }^{4}$ Professor, Department of Ophthalmology, Sri Ramachandra Medical College and Research Institute, Porur, Chennai. \\ 5 Professor \& Head, Department of Neonatology, Sri Ramachandra Medical College and Research Institute, Porur, Chennai.
}

ABSTRACT

AIM

To identify the various ocular ailments in children with developmental problems.

\section{MATERIALS AND METHODS}

418 children who attended the child development unit in a tertiary care centre during a period of 2 years from January 2014 to December 2015 were retrospectively analysed. A detailed data sheet which included their socio-demographic details, systemic ailments, ocular examination and correlations analysed. Ophthalmic examination included examination of lid and adnexa, anterior and posterior segment examination and assessment of squint and refraction.

\section{RESULTS}

$75(17.9 \%)$ children had history of consanguinity, $72(17.2 \%)$ were preterm. Speech and language problem was seen in 300 (71.8\%), developmental delay was the second in the list 240 (57.4\%). Refractive error was the leading ocular problem found in 223 (53.35\%) and the most common refractive error was hyperopia. Anisometropia in 18 (4.31\%). Squint in 19 (4.55\%) and nystagmus in 11 (2.6\%). Though vitamin A deficiency was diagnosed as a leading cause of blindness in developing countries, xerophthalmia was noted in only $1(0.2 \%)$ child.

\section{CONCLUSION}

Children with multi-system involvement are at high risk of visual disabilities and should not be ignored, as these children depend heavily on their vision. There is an increased risk of refractive errors, anisometropia, fusion mechanisms and accommodation and thus orthoptic and optometric support are mandatory. Ocular problems in these children are usually correctable and early diagnosis and treatment will improve their quality of life.

\section{KEYWORDS}

Developmental Assessment, Refractive Errors, Anisometropia, Squint.

HOW TO CITE THIS ARTICLE: Thomas M, Vaishnavi R, Gayathri N, et al. Retrospective analysis of ophthalmic ailments in children attending the child development unit in a tertiary care hospital in south India. J. Evolution Med. Dent. Sci. 016;5(46):2934-2937, DOI: $10.14260 /$ jemds/2016/682

\section{INTRODUCTION}

Ocular ailments are common among children with developmental problems. Each of the five senses is a doorway to the developing mind and vision integrates all other senses. Vision is the primary data gathering system or it is the feedback system for all other developing systems during early stages of life. Size, shape, colour, distance and spatial orientation, all can be perceived in one glance and $75 \%$ of overall development during infancy and early childhood depends on vision. "There are an estimated 25,000 blind and partially sighted children and young people aged 0 -16 years in Britain." (Morris and Smith, 2008).

If born without sight developmental milestones will be delayed, may develop abnormal facial expressions, all the

Financial or Other, Competing Interest: None.

Submission 08-05-2016, Peer Review 20-05-2016,

Acceptance 23-05-2016, Published 09-06-2016.

Corresponding Author:

Dr. Mary Thomas,

Associate Professor,

Department of Ophthalmology,

Sri Ramachandra Medical College and Research Institute,

Porur, Chennai-600116, Tamilnadu, India.

E-mail: marysanthoshj@yahoo.co.in

DOI: $10.14260 /$ jemds/2016/682 other senses may appear diminished because of intermittent unverified visual input. Children with intellectual disability often have to depend mainly on their visual systems to communicate and interact with their surroundings. Diagnosis and timely restoration of vision, as in congenital cataract will have a positive impact on child's growth and development.

In children with complex and multiple disabilities, ocular problems are relatively common, but may often go unnoticed as the focus may be on other aspects of health or management or these disabilities may complicate the accurate assessment of visual function.(1,2) Eye problems sometimes may be mistaken for learning disabilities. Children with very severe attention difficulties may not be able to maintain fixation during vision testing and are at risk of being misdiagnosed as 'blind.'

Children with learning difficulties may experience emotional problems like anxiety, depression and low selfesteem. Those with worsening sight may show aggressive behaviour and may be in need of supportive services. Visual impairments have considerable economic costs both directly due to the cost of treatment and indirectly due to decreased ability to work.(3) It also has substantial impact on family's well-being by causing depression or increasing stress to the parents due to overburden, increase in healthcare cost and subsequent financial difficulties. 
"Visual impairment" refers to all degrees of reduction in vision, which means functional vision and perceptual vision. Functional vision refers to a variety of specific functions of the eye and the neurological control of these functions such as binocularity, pursuit, saccades, accommodation, convergence etc., while perceptual vision refers to understanding, identifying and judging the importance of what you see. Children with developmental problems may be having physical impairment, sensory impairment, cognitive or intellectual impairment, mental illness or various types of psychological problems. All these are hurdles for an accurate identification of the type of visual impairment.

Psychological distress has been noticed in children with visual ailments and is highest when sight loss is not complete. Therefore, early intervention is imperative for enabling successful psychological adjustment.(4)

\section{MATERIALS AND METHODS}

This is a retrospective analysis of records of children attending child developmental unit in a tertiary care centre attached to a Medical College in Chennai. This child development unit offers to children, general paediatric, neurological examination, psychological evaluation, developmental assessment, ophthalmic evaluation, speech and language evaluation, physiotherapy, psychological and educational evaluation using standardised scales and nutritional assessment as a package under one roof. In our study we had analysed the case records of 418 children who attended the child development unit during a period of 2 years from January 2014 to December 2015.

Relevant data sheets which included socio-demographic characteristics, birth history, developmental history, orthoptic assessment, dilated fundus examination with indirect ophthalmoscope, retinoscopy, final diagnosis and treatments provided are all collected and recorded in a prepared data collecting format for each child.

Ethical clearance to conduct the analysis was obtained from the Institutional Ethical Committee.

All children attended the child development unit for developmental assessment during the above mentioned period were included in the study except those who found to be normal on assessment.

All ophthalmological care was offered by two ophthalmologists and two optometrists.

As per the records all children were examined for their head posture, eye movements, fixation, ocular alignment and involuntary movements (Nystagmus). Adnexa examination, orthoptic assessment, cycloplegic refraction using $1 \%$ cyclopentolate and indirect ophthalmoscopy results were all documented. Visual acuity was assessed according to their intelligence and responsiveness. In nonverbal children it was assessed as central or not, steady or unsteady, maintained fixation or occasional response, i.e. CSM (Central, steady, maintained).

Children less than 2 years with good co-operation and response Lea paddles, 2-4 years Lea symbols or single optotypes such as Landolt C or HOTV (Simson 1983) was used and above 5 years Snellen's chart was used.

\section{Statistical Analysis}

All data were entered and analysed by the statistical package for the social sciences (SPSS for windows, version 16). Descriptive statistics included the mean and standard deviation for numerical variables and the percentage of different categories for categorical variables. The prevalence rate of eye problems was described in simple proportion. Group comparisons were done by the Chi-squared $\left(\mathrm{x}^{2}\right)$ test. $\mathrm{P}=$ value of $<0.05$ was considered significant.

\section{RESULT}

Total of 418 children consisting of 279 male children and 139 female children age ranging from 2 months to 204 months (17 years) with a mean of 47.66 months were included in this study of 2 years' duration.

Various systemic problems encountered are shown in Table 1 and ocular ailments in Table 2.

Most common systemic ailment observed was speech and language problem seen in 300 (71.8\%) children. Second in the list was developmental anomaly, seen in 240 (57.4\%).

For refractive errors following criteria were taken into account. Visual impairment (VI) $<6 / 18$ in the better eye, Severe Visual Impairment (SVI) $<6 / 60$ in the better eye and blindness $<3 / 60$ as corrected visual acuity in the better eye (WHO category 1977). Hypermetropia was defined as >+2.0 D spherical equivalent in either eye, myopia as $>-1.50 \mathrm{D}$ spherical equivalent in either eye and anisometropia as a difference $>1.0 \mathrm{D}$ spherical equivalent between the eyes.

Refractive error was the most common ocular problem observed. Refraction showed hypermetropia in 99 (23.68\%), myopia in 19 (4.55\%), astigmatism in 108 (25.84\%) children. Highest hypermetropic power seen was +5.50D, myopia 9.00D and highest astigmatism was -7.00D cylinder.

Second highest in the list was squint; 19 (4.55\%) children had squint. Next in the list was nystagmus 11 (2.6\%). Though literature wise vitamin A deficiency is a major problem in many of the developing countries, Bitot's spots was noticed only in 1 child $(0.2 \%)$.

Out of 18 children with Down's Syndrome (DS), 10 $(55.55 \%)$ had hyperopia of highest power noted was + 4.50D; $7(38.88 \%)$ had accommodative problem and got corrected with bifocals. Others were either emmetropic or with insignificant power. Other than epicanthal fold and mongoloid slant 3 (16.7\%), each had blepharitis and nasolacrimal duct obstruction. Cataract and optic atrophy in 1 (5.6\%) each. Others had normal fundus; 12 (66.66\%) children with DS had developmental delay. Speech and language affected in 13 (72.2\%). None of DS had seizers or Hypoxic Ischaemic Encephalopathy (HIE).

Among 15 children with cerebral palsy (CP), 5 (33.5\%) had seizures, $4(26.7 \%)$ had HIE, while 29 (7.2\%) children without $\mathrm{CP}$ had HIE and is statistically significant [ $\mathrm{p}=0.24]$. Though not statistically significant speech and language affected in 13 $(86.7 \%)$, cognitive function was impaired in $5(33.3 \%)$ and developmental delay in 11 (73.3\%), spastic limbs in 7 (46.67\%), MR and microcephaly in 2 (13.3\%) each.

Ocular ailments in children with CP included 6 (40\%) hyperopia, $1(6.7 \%)$ myopia, squint in $2(13.3 \%)$, cataract in 1 (6.7\%), Optic atrophy and temporal pallor in $2(13.3 \%)$ each. VI was present in 6 (40\%).

Overall incidence of autism in this study was 72 (17.2\%), 17 (23.6\%) had hyperopia; 2 (2.78\%) had myopia. Highest astigmatism noted was $+4.50 \mathrm{D}$ cylinder and $-7.50 \mathrm{D}$ cylinder. No lid and adnexa problems were noticed. Fundus was normal in all autistic children. Visual impairment was present in 5 $(6.9 \%)$. 
Attention Deficit Hyperactivity Disorder (ADHD) was present in 46 (11\%). Commonest ocular problem in them was refractive error - hyperopia in $9(19.56 \%)$ and myopia in 5 (10.87\%), 1 (2.17\%) had squint and 5 (10.86\%) had VI.

Mental Retardation (MR) was seen in $16(3.8 \%)$ in which VI in 7 (43.75\%), nystagmus in $2(12.5 \%)$, squint in 3 (18.75\%), cataract in $1(6.25 \%)$, hyperopia in 4 (25\%), myopia in $2(12.5 \%)$.

\begin{tabular}{|c|c|c|c|}
\hline Sl. No. & Condition & No. & $\mathbf{\%}$ \\
\hline 1 & Speech and language & 300 & 71.8 \\
\hline 2 & Developmental delay & 240 & 57.4 \\
\hline 3 & Hearing impairment & 31 & 7.4 \\
\hline $4^{+}$ & HIE & 33 & 7.9 \\
\hline 5 & Meningitis & 4 & 1 \\
\hline 6 & Hydrocephalus & 6 & 1.4 \\
\hline $7^{*}$ & Associated anomalies & 40 & 9.6 \\
\hline 8 & Cognitive impairment & 95 & 22.7 \\
\hline 9 & Down's syndrome & 18 & 4.3 \\
\hline 10 & Cerebral palsy & 15 & 3.6 \\
\hline 11 & Mental retardation & 16 & 3.8 \\
\hline 12 & ADHD & 46 & 11 \\
\hline 13 & Autism & 72 & 17.2 \\
\hline 14 & Hemiparesis & 16 & 3.8 \\
\hline 15 & Spastic limbs & 12 & 2.87 \\
\hline 16 & Microcephaly & 22 & 5.3 \\
\hline 17 & Seizures & 33 & 7.9 \\
\hline \multicolumn{4}{|c|}{ Table 1: Systemic Conditions Observed } \\
\hline \multicolumn{4}{|c|}{} \\
\hline \multicolumn{4}{|c|}{} \\
\hline
\end{tabular}

+Hypoxic ischaemic encephalopathy.

*Associated anomalies like under development of Corpus callosum, dysmorphic features, Dandy-Walker syndrome, West syndrome, cardiac problems, Cyanotic heart disease, trachea-oesophageal fistula, etc.

\begin{tabular}{|c|c|c|c|}
\hline Sl. No. & Ocular Condition & No. & \% \\
\hline 1 & Refractive error & 223 & 53.35 \\
\hline 2 & Lid and Adnexa problem & 7 & 1.7 \\
\hline 3 & Nystagmus & 11 & 2.6 \\
\hline 4 & Squint & 19 & 4.55 \\
\hline 5 & Bitot's spots & 1 & 0.2 \\
\hline 6 & Cataract & 5 & 1.2 \\
\hline 7 & Iris coloboma & 1 & 0.2 \\
\hline 8 & Hypoplastic disc & 1 & 0.2 \\
\hline 9 & Optic atrophy & 7 & 1.7 \\
\hline 10 & Temporal pallor & 7 & 1.7 \\
\hline \multicolumn{3}{|c|}{ Table 2: Ocular Problems Observed } \\
\hline \multicolumn{3}{|c}{} \\
\hline
\end{tabular}

\section{DISCUSSION}

The most common refractive error in our study was hypermetropia $\geq+2.00 \mathrm{D}$ seen in $99(23.68 \%)$. In our study Myopia was seen in $4.55 \%$ and astigmatism of $\geq 1.0 \mathrm{D}$ was seen in 108 children (25.84\%). According to Alison Salt et al, hypermetropia was seen in $44 \%$ of disabled children, myopia in $11 \%$ and astigmatism was seen in $20.6 \%$ of disabled children.(5)

The second common problem in our list was squint, seen in 19 (4.55\%) children, while in Alison salt et al study 27\% children had strabismus.

In our study, 18 children had Down's Syndrome (DS), out of which $55.55 \%$ had hyperopia of $\geq 2.0 \mathrm{D}$, which was similar to Alison salt et al study.
According to Arsen A, Ozgur O, Ozlem H, et al, moderateto-high refractive errors are much more common in DS than in the general population. Hypermetropia $>+2.00 \mathrm{D}$ in $62 \%$ in DS and $16 \%$ in non-DS and myopia $<0.50 \mathrm{D}$ in $8 \% \mathrm{DS}$ and $77 \%$ in non-DS.(6) In our study $55.55 \%$ had hyperopia of $>+2.0 \mathrm{D} ; 7$ (38.88\%) had accommodative problem and this is much less compared to Creg M, Haugen $\mathrm{OH}$ study where they have shown $55-68 \%$ children with DS have significant lag of accommodation. $(7,8)$

Shapiro M has observed blepharitis in $47 \%$ of DS, but in our study we have seen only $5.6 \%$. ${ }^{(9)}$

Cataract though rare in DS occurs more commonly than in general population.(10) and the present study showed 5.65\%. The prevalence of squint is found to be $29-42 \%$ in DS.(11) In our study none of them had squint, while in Alison et al had $25 \%$ of the Down syndrome suffering from strabismus. But according to Siegfried Pueschel and Stefan Gieswein had 50\% DS population suffering from strabismus, which was more than usual.(12) Caputo, Wagner and Reynolds (1989) examined 187 patients with DS and found that $57 \%$ of the study individuals had strabismus. Hiles, Hoyme and McFarlane (1974) noted that $34 \%$ of 123 patients with DS had either esotropia or exotropia. This difference in result may be due to small sample size (18 DS cases out of 418 children).

In our study $3(16.7 \%)$ had blepharitis, whereas children without DS $4(1 \%)$ had blepharitis and this difference is statistically significant $[\mathrm{P}=0.002]$. Though not statistically significant, developmental delay was found more among children with DS 12 (66.7\%) when compared to children without DS 228 (57.0\%).

In India vast majority of Cerebral Palsy (CP) patients have spastic CP (91.4\%).(13) Spastic limbs was seen in (46.67\%) in our study. Spasticity and blindness are a bad combination since through touch, "the hands of the blind become their eyes."(14)

In CP squint was seen in 2 (13.3\%). Cataract was seen in 1 $(6.75 \%)$. In our study $6(40 \%)$ had hyperopia of $\geq+2.0 \mathrm{D}$, while in Woo et al hyperopia was seen in $46.6 \%$, while in Sasmal et al the incidence of hyperopia in cerebral palsy was $8.6 \% .^{(15)}$ In our study, myopia was found in $6.7 \%$. While in Sasmal et al, myopia was seen in $12.9 \%$ children.

Overall incidence of autism in this study was 72 (17.3\%), $17(23.6 \%)$ had hyperopia of $\geq 2.0 \mathrm{D}, 2(2.78 \%)$ had myopia of $>-1.50 \mathrm{D}$. Highest astigmatism noted was $+4.50 \mathrm{D}$ cylinder and -7.50 D cylinder. No lid or adnexal problem noticed. Fundus was normal in all autistic children. Denis et al hypermetropia was seen in $70 \%$ of the autistic children.(16)

While in Denis et al, strabismus was seen in $60 \%$ of the case.(16) In our study, none of the autistic children had squint.

In children with mental retardation, hyperopia was seen in 4 (25\%), myopia in $2(12.5 \%)$. But Rajesh and Abhishek et al has observed myopia $60 \%$ and hypermetropia in $20 \%$.(17) Refractive errors and strabismus have also been found to be correlated with low IQ.(18) Overall commonest refractive error seen was hyperopia.

In children with disability, attention span is short and they will be quickly bored by the vision checking methods so that subjective assessment may not be accurate. As letters become smaller in the chart, they may become unresponsive or lose interest. As a visually impaired child grows older, although acuity may remain constant visual function seems to improve as they gradually learn how to use the residual vision more. 
Children as they are born with an immature visual system, it needs a clear image to be transmitted to the higher visual centres for the normal visual development. So there is an urgency about diagnosing and treating childhood eye problems before the development of amblyopia and there will be a better acceptance to rehabilitation measures. We have seen that most of the children with profound disabilities are having sight problems. Regular eye examinations and corrective measures will make them stay healthy and get the most from life. Otherwise, finally family and society has to face the challenge of providing financial and supportive measures.

\section{CONCLUSION}

A clear cut knowledge about the visual problems in children will help in the prevention of vision impairment at three levels, primary prevention by creating a social awareness as to how to prevent the occurrence of the disease, secondary by managing the actual disease process and tertiary prevention of blindness by restoring vision by measures like cataract surgery, correction of refractive errors, amblyopia correction and by providing magnifiers and other low vision aids to restore useful visual function or other rehabilitative measures. Usually children with mental and physical disability are not examined with care due to difficulty in making an assessment or due to a presumption that nothing much can be done.

But a proper examination with patience will help to detect various ocular problems at an early stage and to provide corrective treatment, so that their psychomotor development will be better, quality of life and social interaction will improve and they will learn how to improve within their limitations. It is important to organise a multidisciplinary system with paediatrician at the centre to detect these conditions early in life. They can work in a more coordinated way for a consensus regarding detailed assessment and also to provide practical guidelines for the individual child.

\section{LIMITATION OF THE STUDY}

In this study, only ocular ailment analysis is done. Extensive study regarding the management of the problem specific to each child and outcome of management also has to be studied in subsequent analysis and an approach to assessment and management should be outlined.

Children with learning disabilities are found to have serious sight problems than other children and those children are not particularly analysed in this study.

It can be noted that all premature children coming for follow-up in the child development unit are given early visual stimulation cards with black and white patterns. There is a definite improvement in these children, but a controlled study only can prove the significance of early visual stimulation.

\section{ACKNOWLEDGEMENT}

We would like to acknowledge the Department of Paediatrics and the child development unit. Further we acknowledge Dr. Ravi Shankar, Department of Community Medicine, for the statistical assistance.

\section{REFERENCES}

1. Woodhouse JM, Davies N, McAvinchey A, et al. Ocular and visual status among children in special schools in wales: the burden of unrecognised visual impairment. Arch Dis Child 2014;99(6):500-4.
2. Welinder LG, Baggesen KL. Visual abilities of students with severe developmental delay in special needs education-a vision screening project in Northern Jutland, Denmark. Acta Ophthalmol 2012;90(8):721-6.

3. Rein DB. Vision problems are a leading source of modifiable health expenditures. Investigative Ophthalmology \& Visual Science 2013;54(14):18-22.

4. De leo D, Hickey PA, Meneghel G, et al. Blindness, fear of sight loss, and suicide. Psychosomatics 1999;40(4):33944.

5. Salt A, Sargent J. Common visual problems in children with disability. Arch Dis Child 2014;99(12):1163-8.

6. Akinci A, Oner O, Bozkurt OH, et al. Refractive errors and strabismus in children with down's syndrome: a controlled study. J Paediatr ophthalmol Strabismus 2009;46(2):83-6.

7. Cregg M, Woodhouse JM, Pakeman VH, et al. Accommodation and refractive errors in children with down's syndrome: cross-sectional and longitudinal studies. Investigative Ophthalmol Vis Sci 2001;42(1):5563.

8. Haugen $\mathrm{OH}$, Hovding G. Strabismus and binocular function in children with down's syndrome. A population based longitudinal study. Acta Ophthalmol Scand 2001;79(2):133-9.

9. Shapiro MB, France TD. The ocular features of down's syndrome. Am J Ophthalmol 1985;99(6):659-63.

10. Kellen B, Mastroiacovo P, Robert E. Major congenital malformations in down's syndrome. Am J Med Genet 1996;65(2):160-6.

11. Woodhouse JM, Pakeman VH, Cregg M, et al. Refractive errors in young children with Down syndrome. Optom Vis Sci 1997;74(10):844-51.

12. Pueschel SM, Gieswein S. Ocular disorders in children with down syndrome. Down Syndrome: Research and Practice 1993;1:129-32.

13. Mutch L, Alberman E, Hagberg B, et al. Cerebral palsy epidemiology: where are we now and where are we going? Dev Med Child Neurol 1992;34(6):547-51.

14. Jan JE, Freeman RD, Scott EP. The multi-handicapped visually handicapped children. In: Visual impairment in children and adolescents. Grune and Stratton: New York 1977; 75-81.

15. Sasmal NK. Ophthalmologic signs in children with autism. J Indian Med Assoc 2011;109(5):318-23.

16. Denis D, Burillon C, Livet MO, et al. Ophthalmologic signs in children with autism. J Fr Ophthalmol 1997;20(2):103-10.

17. Rajesh SJ, Abhishek AS. Ocular disorders in children with mental retardation. Indian J Psychiatry 2013;55(2):1702.

18. Nielsen LS, Skov L, Jensen H, et al. Visual dysfunctions and ocular disorders in children with developmental delay. I. prevalence, diagnoses and aetiology of visual impairment. Acta Ophthalmol Scand 2007;85(2):14956. 